\section{Author reply}

$\mathrm{W}$ e read the letter with great caution. Dr Eduardo Cuestas showed great interest in the procedure of air insufflation for acute intussusception in young baby. What he concerns is just a single question, i.e., whether the tube connecting the anus and the machine is occlusive. In fact, with an automatic insufflation machine, the air pressure was manually set and then controlled automatically. Hence no additional control is needed for the connecting tube. With the aid of such automatic insufflation machine, the advantages quoted in the letter can be reached.

We are highly grateful to Dr. Cuestas for his interest in our paper and are pleased to respond to any query.

Fei-Teng Kong and Yun-Man Tang

Department of Pediatric Surgery,

West China Hospital of Sichuan University,

Chengdu 610041, China

doi: $10.1007 / \mathrm{s} 12519-011-0274-8$

\section{Editor's note}

$\mathrm{W}$ e are grateful to Dr. Eduardo Cuestas for his mention of the first description of controlled insufflation of air for diagnosis and treatment of intestinal intussusception by Fiorito et al in $1953 .^{[1]}$ So that we could understand the history of pneumatic insufflation as a diagnostic and therapeutic modality for intestinal intussusception. However, Fiorito et al's patients were all between 3 and 18 months of age.

Intussusception is often seen in children aged between 4 months and 2 years with the peak incidence during 4 to 9 months. Infants younger than 3 months rarely suffer from this disease, and the treatment in this age group is mentioned less in the international literature and is a challenge for the clinician. The article by Kong et $\mathrm{al}^{[2]}$ adds further information to clinical presentations and management of intussusception in infants younger than 3 months.

However, issues that deserve further clarification remain, for example, the proportion of infants younger than 3 months in all children with intussusception, the proportion of neonates in all children with intussusception, the diagnosis and treatment of intestinal intussusception in infants younger than 1 month.

We invite our readers to participate in this discussion and to provide articles and information on the clinical presentations and management of intussusception in infants younger than 3 months.

Min-Ju Li, MD

Deputy managing editor

World Journal of Pediatrics

Children's Hospital, Zhejiang University School of Medicine

Hangzhou 310003, China

\section{References}

1 Fiorito ES, Recalde Cuestas LA. The "controled insufflation" (baro-fluoroscopically), method of choice for the diagnosis and treatment of intussusception in infants. Rev Soc Pediatr Litoral 1953;18:3.

2 Kong FT, Liu WY, Tang YM, Zhong L, Wang XJ, Yang G, et al. Intussusception in infants younger than 3 months: a single center experience. World J Pediatr 2010;6:55-59.

doi: 10.1007/s12519-011-0275-7 